\title{
Removal of a migrated fully covered metal biliary stent by cholangioscope-assisted inversion technique
}

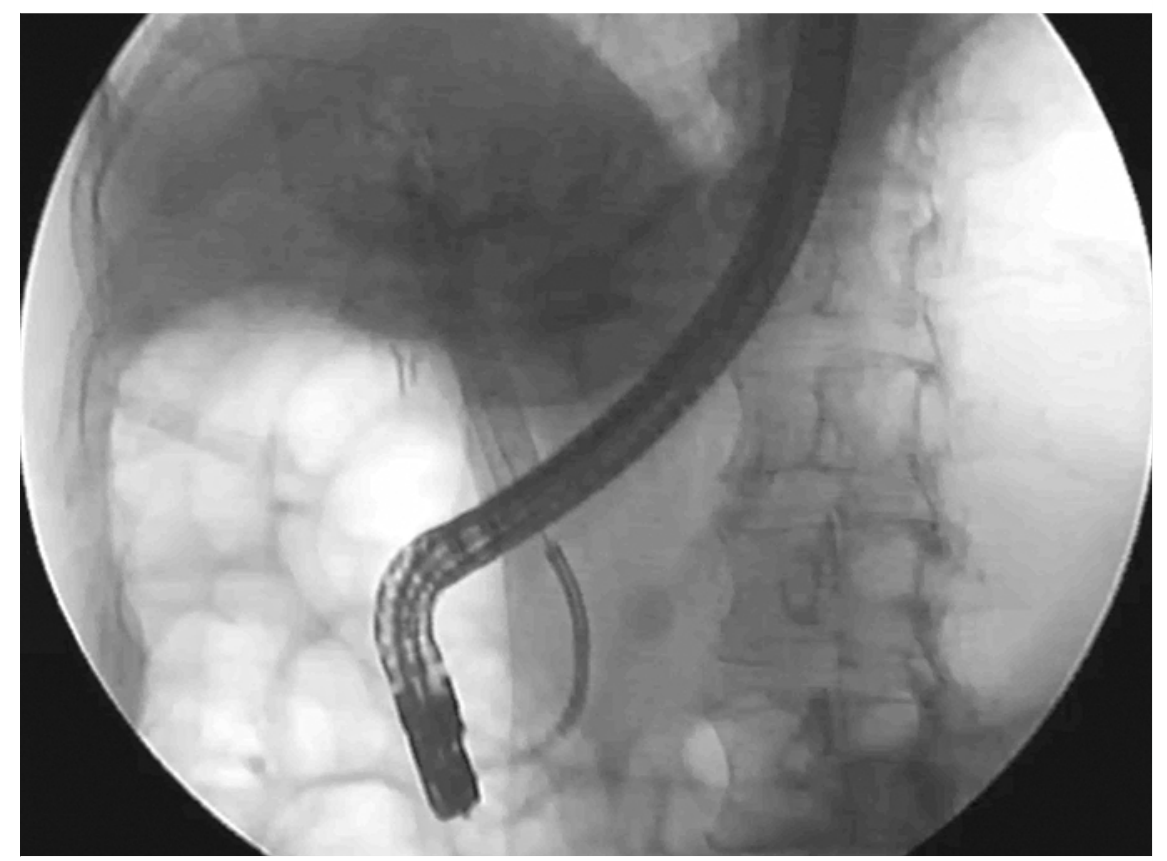

- Fig. 1 Fluoroscopic image of proximally migrated stent and cholangioscope.

Proximal biliary stent migration is a rare and unwanted complication. Various endoscopic methods have been used to remove migrated biliary stents, including the use of direct cholangioscopy for plastic biliary stent migration [1-4]. Here, we describe a case of cholangioscopy-assisted removal of a proximally migrated fully covered metal biliary stent by inversion technique.

A 78-year-old woman with metastatic pancreatic head adenocarcinoma initially presented to an outside facility with jaundice due to biliary compression. Endoscopic retrograde cholangiopancreatography (ERCP) with placement of two fully covered self-expandable metal stents (FCSEMS) was performed at the outside facility. Several days later, the patient presented to our facility with persistent jaundice. Serum bilirubin was $20 \mathrm{~g} / \mathrm{dL}$. A repeat ERCP was then performed at our facility.

Initial fluoroscopy showed two biliary stents in the common duct. Endoscopic view, however, revealed only one stent emanating from the ampulla. Cholangiogram showed that that the second stent had migrated upward into the common hepatic duct (CHD) adjacent to the nonmigrated stent. The nonmigrated stent was removed, and cholangioscopy using SpyGlass DS Direct Visualization System (Boston Scientific Corp., Marlborough, Massachusetts, USA) was performed to visualize the migrated stent ( $\triangleright$ Fig.1). The migrated stent was in the oblique position, partially obstructing the CHD. In order to remove the migrated stent, SpyBite Biopsy Forceps (Boston Scientific Corp.) via cholangioscopy was used to grasp the proximal portion of the migrated stent and invert it inward while pulling the stent downward ( Fig.2, > Fig. 3, - Video 1). A Radial Jaw 4 Pediatric Biopsy Forceps (Boston Scientific Corp.,) was then used to fully remove the migrated stent ( $\boldsymbol{F i g . 4}$ ).

Endoscopy_UCTN_Code_CPL_1AK_2AC

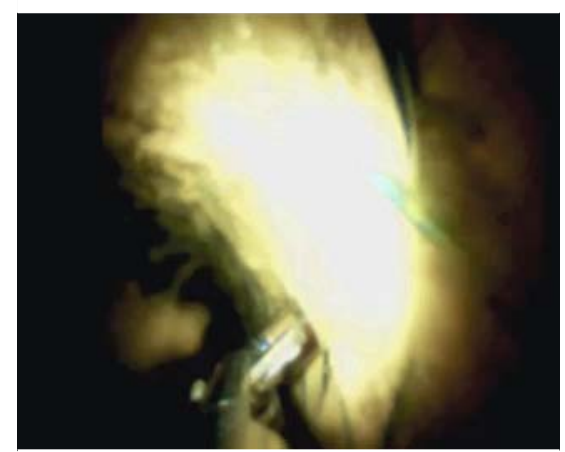

- Fig. 2 Proximal portion of the stent being grasped by SpyBite Biopsy Forceps (Boston Scientific Corp., Marlborough, Massachusetts, USA).

Competing interests

None

The authors

Erik Rahimi ${ }^{1}$, Samreen Khuwaja ${ }^{2}$, Nirav Thosani ${ }^{1}$

1 Division of Gastroenterology, Hepatology, and Nutrition, UT Health Science Center at Houston, McGovern Medical School, Houston, Texas, United States

2 Department of Medicine, UT Health Science Center at Houston, McGovern Medical School, Houston, Texas, United States

Corresponding author

\section{Erik Rahimi, MD}

Division of Gastroenterology, Hepatology, and Nutrition, UT Health Science Center at Houston, McGovern Medical School, 6431 Fannin St, MSB 4.234 Houston, Tx 77030 , United States

Fax: +1-713-500-6699

erikrahimi@yahoo.com

Erik.f.rahimi@uth.tmc.edu 


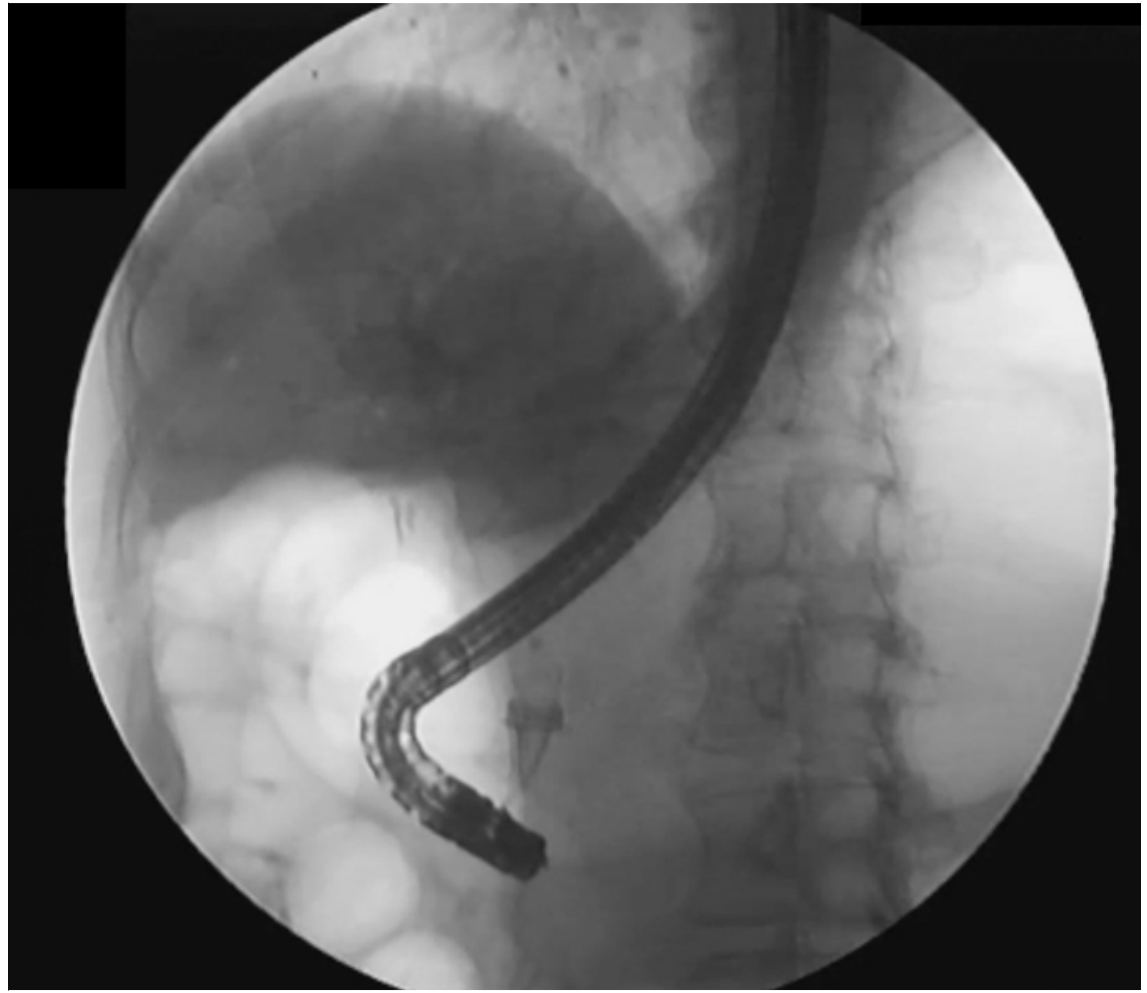

Fig. 3 Inverted biliary stent seen on fluoroscopy.
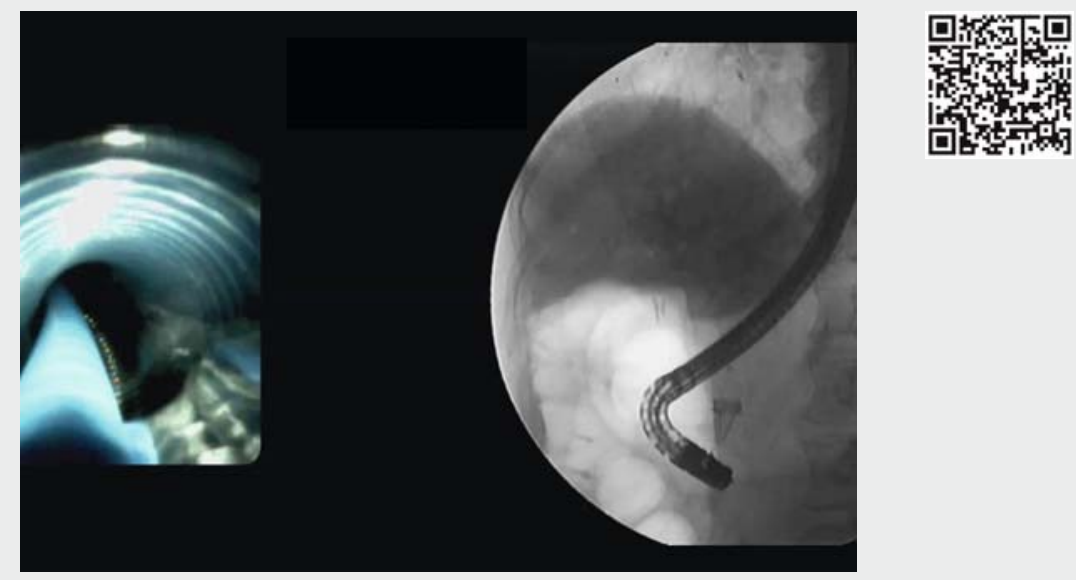

$\checkmark$ Video 1 Cholangioscope-assisted removal of proximally migrated fully covered metal biliary stent. The stent was grasped at its proximal end by SpyBite Biopsy Forceps (Boston Scientific Corp., Marlborough, Massachusetts, USA) and inverted while being pulled downward. Pediatric forceps then removed the inverted stent.

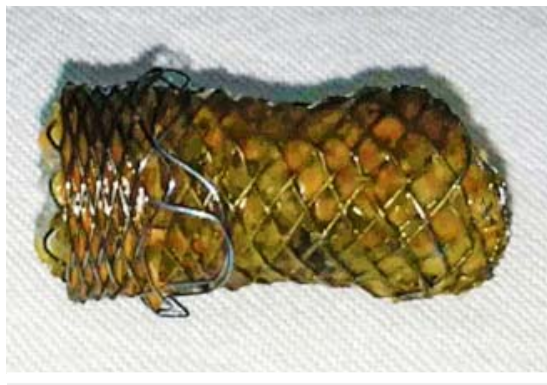

- Fig. 4 Removed migrated biliary stent in inverted state.

References

[1] Wu C, Yang JF, Xu M et al. Endoscopic removal of a proximally migrated biliary metallic stent. Endoscopy 2017; 49 (Suppl. 01): E99-E100

[2] Sanaka MR, Wadhwa V, Patel M. Retrieval of proximally migrated biliary stent with direct peroral cholangioscopy with an ultraslim endoscope. Gastrointest Endosc 2015; 81: $1483-1484$

[3] Sejpal DV, Vamadevan AS, Trindade AJ. Removal of an embedded, migrated plastic biliary stent with the use of cholangioscopy. Gastrointest Endosc 2015; 81: 1482-1483

[4] El Hajj II, Lehman GA, Fogel EL et al. Endoscopic retrieval of a proximally migrated biliary stent: digital cholangioscope to the rescue. VideoGIE 2017; 2: 328 -329

\section{Bibliography}

DOI https://doi.org/10.1055/a-0652-5251

Published online: 31.8.2018

Endoscopy 2018; 50: E312-E313

(c) Georg Thieme Verlag KG

Stuttgart · New York

ISSN 0013-726X

\section{ENDOSCOPY E-VIDEOS}

https://eref.thieme.de/e-videos

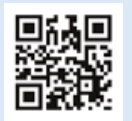

Endoscopy E-Videos is a free access online section, reporting on interesting cases and new techniques in gastroenterological endoscopy. All papers include a high quality video and all contributions are freely accessible online.

This section has its own submission website at

https://mc.manuscriptcentral.com/e-videos 